PAPERS

\title{
Breast problems in 1,000 consecutive referrals to surgical out-patients
}

\author{
HAROLD ELLIS \\ D.M., M.Ch., F.R.C.S.
}

PETER J. COX

B.Sc., M.B., F.R.C.S.

\author{
Surgical Unit, Westminster Hospital, London SWI
}

\begin{abstract}
Summary
One-thousand consecutive referrals of breast complaints to surgical out-patients are presented with breakdown according to the pathological groups of final diagnoses. The relationship of these groups to parity, breast feeding and age are discussed as also is the clinical management of these cases.
\end{abstract}

KEY WORDS: general surgical out-patients, breast disease, breast carcinoma.

\section{Introduction}

The Professorial Surgical Unit at Westminster has had an interest in breast problems for some time and sees them as part of general surgical out-patients, not at a specialized breast clinic. We were interested to see whether the type and range of disease in surgical out-patients would differ from that of a specialized referral centre, or present different problems to the general surgeon. Previous studies (Chetty et al., 1980) have been from specialized centres. We prospectively documented all cases referred to out-patients with problems relating to the breasts in order to identify the work load afforded by breast complaints to the general surgeon. This ongoing study has been presented previously at interim stages (Cox, $\mathrm{Li}$ and Ellis, 1982; Cox and Ellis, 1982) and was stopped when referrals reached 1,000 cases.

\section{Methods}

Criteria for inclusion into this study were: any patient of either sex referred by the general practitioner, or intra-hospital consultant referral with a problem relating to the breasts. Patients from Well Women and Breast Screening Clinics were referred by their general practitioners.

Patients were indexed at their first out-patient attendance and data collected on cards with a backup assimilation by computer to assist in compiling results. Any subsequent out-patient or in-patient visit was then added to the cards so a profile of initial diagnosis to final diagnosis and treatment was achieved.

At the initial out-patient visit a full history was taken with a special reference to parity, menopausal status, breast feeding, oral contraceptives, previous breast disease and family history of breast disease.

Biopsy was arranged for all patients over 30 with a palpable lump except those thought to be macroscopic breast cysts. Less urgent biopsy was arranged for women below 30 with obvious fibroadenomas. Aspiration of lumps thought to be cystic was performed with a fine needle at the initial out-patient visit. If this was unsuccessful, or if the aspirate was blood stained, or if the lump did not completely disappear urgent biopsy was arranged. Cytology or microbiology of the aspirant was not carried out as it has been shown to be unhelpful if the above criteria are adhered to (Jones and Bradbeer, 1980; Cowen and Benson, 1979). Patients with successfully aspirated cysts were reviewed at 6 weeks and any reaccumulation or new cysts re-aspirated, observing the same criteria for biopsy as above (vide infra).

Mammography was used in cases of breast thickening and pain in women between the ages of 30 and 50 years where the diagnosis was probably one of fibroadenosis. Any woman over 50 with a palpable thickening had a biopsy. If this was diffuse, a mammogram occasionally helped to pin-point the area to biopsy. Some patients were referred from screening clinics with positive mammograms for biopsy. A policy of lumpectomy and radical radiotherapy for breast cancer allowed us to carry out routine biopsy on all cases and consent was sought only for this procedure (vide infra).

Cysts containing aspiratable amounts of fluid differ from the microscopic cysts found in cystic mastopathy. The fibroadenosis group includes the latter term and also all dysplasia with an overgrowth of ductal or stromal tissue, encompassing such pathological terms as duct ectasia, sclerosing adenosis, chronic mastitis and fibroadenomatous hyperplasia. 
TABLE 1. Final diagnosis and age range in 1,000 consecutive surgical unit referrals with breast problems.

\begin{tabular}{lrcc}
\hline & $n$ & Age range (years) & Mean (years) \\
\hline All & 1,000 & $13-83$ & 40 \\
Normal & 306 & & 39 \\
Fibroadenosis & 223 & $18-67$ & 43 \\
Cysts & 150 & $19-63$ & 56 \\
Cancer & 118 & $27-83$ & 28 \\
Fibroadenoma & 77 & $13-83$ & \\
Abscess & 11 & & \\
Lipoma & 16 & & \\
Miscellaneous & 74 & & \\
Undiagnosed & 25 & & \\
\hline
\end{tabular}

\section{Results}

Twenty-two patients were male, 11 of whom had mastitis of puberty and six had senile gynaecomastia. The latter could usually be related to drug therapy and settled conservatively, only one obvious carcinoma of the male breast was seen and one doubtful breast enlargement was biopsied and found to be benign gynaecomastia.

Table 1 shows the final diagnosis of all cases. Just under one-third were considered to have normal breasts whilst nearly a quarter had fibroadenosis. Cysts accounted for $15 \%$ and carcinoma of the breast accounted for nearly $12 \%$.

TABLE 2. Excision biopsy results in 457 cases

\begin{tabular}{lrr}
\hline & $n$ & $\%$ \\
\hline Cancer & 118 & 26 \\
Fibroadenosis & 167 & 37 \\
Fibroadenoma & 77 & 17 \\
Cyst & 24 & 5 \\
Lipoma & 16 & 3 \\
Normal & 12 & 3 \\
Miscellaneous & 43 & 9 \\
\hline
\end{tabular}

The biopsy rate in this series was $46 \%$ and the results of these are shown in Table 2; 126 patients were treated by aspiration of cysts alone. Thus 417 patients required no active treatment. The 74 miscellaneous diagnoses included the mastitis of puberty
(11) and senile gynaecomastia (6). There were seven 3 . cases of inflammation of the breast of unknown' aetiology which settled spontaneously. There were five intra-duct papillomas and five cases of Tietze'sळ syndrome. Other rarer conditions occurred ranging from sebaceous cysts, normal fatty nodules to cysto- $\omega$ sarcoma phylloides and secondary carcinoma in the으 breast skin.

The age distribution was looked at overall for the four major groups-carcinoma, fibroadenoma, 0

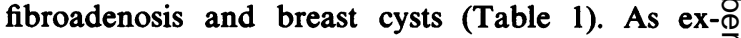
pected, carcinoma occurred particularly in postmenopausal women over two-thirds of whom wewe over the age of 50 years. The fibroadenomas $88-$ curred in the young. We had a single patient aged 83 years but the rest were below 47 years. The fibroadenosis patients were scattered beyond the menopause. In contrast, the patients with macroscopic breast cysts were also found mainly in the $\stackrel{\mathbb{Q}}{\mathbb{Q}}$ menstrual years but with a very sharp cut off after $\overrightarrow{\vec{F}}$ the menopause.

Table 3 shows the parous state and breast feeding rate for the four main diagnostic groups and others. The pregnancy rate in the fibroadenoma group was lower due to the younger age of these patients, that of 3 . the other groups being similar and none of the differences reaching statistical significance. The breast feeding rate is of interest in that patients with $\delta$ cysts had the highest number of women who had breast fed. This however did not quite reach statisti-윽

TABLE 3. Parity and breast feeding according to final diagnosis

\begin{tabular}{lcccccc}
\hline & $\begin{array}{c}\text { Number in } \\
\text { diagnostic } \\
\text { group }\end{array}$ & $\begin{array}{c}\text { Parous } \\
n\end{array}$ & $\begin{array}{c}\% \text { of } \\
\text { total }\end{array}$ & \multicolumn{2}{c}{ Breast feeding } & (\% of parous) \\
\hline Cancer & 118 & 73 & 62 & 36 & $(49)$ \\
Fibroadenoma & 77 & 31 & 40 & 13 & $(42)$ \\
Fibroadenosis & 223 & 140 & 63 & 64 & $(46)$ \\
Cysts & 150 & 97 & 65 & 58 & $(60)$ \\
Others & 432 & 206 & 48 & 102 & $(50)$ \\
Total series & 1,000 & 547 & 55 & 273 & $(50)$ \\
\hline
\end{tabular}


cal significance as it had done in the first 500 of our patients to be analysed (Cox and Ellis, 1982).

TABLE 4. Previous benign breast disease according to final diagnosis

\begin{tabular}{lccc}
\hline & $\begin{array}{c}\text { Number in } \\
\text { diagnostic group }\end{array}$ & $\begin{array}{c}\text { Number with } \\
\text { previous benign } \\
\text { breast disease }\end{array}$ & $(\%)$ \\
\hline Cancer & 118 & 8 & $(7)^{*}$ \\
Fibroadenoma & 77 & 17 & $(22)$ \\
Fibroadenosis & 223 & 46 & $(21)$ \\
Cysts & 150 & 60 & $(40)$ \\
Other & 432 & 78 & $(18)$ \\
& 1,000 & 209 & $(21)$ \\
\hline
\end{tabular}

*Statistical significance $P<0.05$ by $\chi^{2}$ when compared to all other cases.

Table 4 shows the rate of previous benign breast disease in these patients according to the four major groups. The very low percentage of cancer patients who had been seen previously for breast problems did reach statistical significance $(P<0.05)$.

\section{Discussion}

Breast problems constitute a considerable portion of surgical out-patient time and a great deal of emotion and stress for the individual patients concerned. It is of interest that the spectrum of disease seen in general surgical out-patients is similar in proportion to that seen at a special diagnostic breast clinic (Chetty et al., 1980). It must not be forgotten that the surgeon's major role is one of reassurance for the patient and referring practitioner as attested by one-third of our cases. Nevertheless, 118 carcinomas have been diagnosed during the period of the trial, one being in a man, emphasizing the importance of careful examination of the male breast.

Aspiration in the out-patients is a simple way of dealing with macroscopic breast cysts and of relieving patients' and doctors' fears. The criteria already defined, however, have to be adhered to strictly. Seventy-one biopsies were undertaken for aspiration that failed for any of these reasons; 28 of these proved to have fibroadenosis but 18 had carcinoma. There were nine cysts that were biopsied after failed aspiration and these were mainly deeply situated or thick walled, which made them difficult to puncture.

The patients with breast cysts were noted by Jones and Bradbeer (1980) to have a higher rate of breast feeding than other groups. This was not borne out to statistical significance in our series, although a trend in that direction has been demonstrated.

When looking at previous benign breast disease statistical significance has been reached by the low number of $7 \%$ of carcinoma patients who had previously been seen by a general practitioner or surgeon for problems relating to the breast. This at first glance is somewhat surprising as many authors state that benign breast disease does impart an increased risk of developing carcinoma of the breast and several prospective trials have shown this. More particularly Harrington and Lesnick (1981) have shown that cysts of the breast impart a $2 \cdot 5$-fold increase in the risk of developing breast cancer. In our series the low rate of previous benign disease may be a reflection of the older age of the carcinoma patient and agrees with the large series from Edinburgh (Chetty et al., 1980), which failed to show that woman diagnosed as having breast cancer have an increased likelihood of having a history of a previous breast complaint.

The biopsy rate of $46 \%$ in this series is higher than previous series reported but this is mainly due to our policy of lumpectomy and radical radiotherapy. Thus in our practice we do not Tru-cut biopsy or aspirate solid breast lumps for a preliminary diagnosis. This has in fact made our practice of management much simpler because all women coming in for biopsy sign a consent just for the biopsy with no threat of mastectomy.

Only four of the carcinoma patients had a biopsy later than 1 month from the initial out-patient appointment, which is at the earliest convenient date from receiving the referral letter. Two of these patients had thickening, which was thought to be fibroadenosis but mammograms revealed suspicious areas. The other two had cysts aspirated at the initial visit and subsequently had unaspiratable lumps at the next out-patients appointment. No patient with carcinoma in this series had the diagnosis delayed longer than 2 months from the initial out-patients referral.

\section{Conclusion}

This series of 1,000 consecutive referrals to a general surgical out-patient clinic shows the spectrum of breast disease which one would expect to see and also confirms that this is no different from referrals to a diagnostic breast clinic, except perhaps for the male patients. Our policy of lumpectomy has allowed us to biopsy all palpable lumps and in this series most palpable lumps in women above the age of 50 years are carcinoma until proven otherwise. Most of the lumps below the age of 30 are benign but in the difficult years of 30 to 50, urgent biopsy has enabled us to establish the diagnosis and treatment at an early stage. Thus, although significant pathology was only found in half the cases and cancers in only $12 \%$, our role of sorting the wheat from the chaff, and mainly one of reassurance to the patient, referring doctor and ourselves, continues in the general surgical outpatients as well as in the diagnostic breast clinic. 


\section{References}

Chetty, U., Wang, C.C., Forrest, A.P.M. \& Roberts, M.M. (1980) Benign breast disease and cancer. British Journal of Surgery, 67, 789.

COWEN, P.N. \& BENSON, E.A. (1979) Cytological study of fluid from breast cysts. British Journal of Surgery, 66, 209.

Cox, P.J. \& Ellis, H. (1982) Spectrum of breast disease in 500 consecutive patients. Breast, Diseases of the Breast, 8, 30.

Cox, P.J., LI, M. \& ElLIS, H. (1982) Spectrum of breast disease in outpatient surgical practice. Journal of the Royal Society of Medicine, 75, 857.
Ellis, H. \& PHILliPS, R.H. (1980) The local treatment of breast cancer. The Practitioner, 224, 1003.

HARRINGTON, E. \& LESNICK, G. (1981) The association between gross cysts of the breast and breast cancer. Breast, Diseases of the Breast, 7, 13.

JONES, B.M. \& BRADBEER, J.W. (1980) The presentation and $\stackrel{\oplus}{\oplus}$ progress of macroscopic breast cysts. British Journal of Surgery 67, 669 .

(Accepted 28 March 1984) 